\title{
Realismo, perspectivismo e a questão da objetividade jornalística
}

\section{Realism, perpectivism and the question of journalistic objectivity}

\author{
Rafael da Silva Paes Henriques \\ Professor do departamento de comunicação social da UFES
}

Resumo: O problema da objetividade jornalística se faz presente desde a mais simples até a mais complexa operação realizada diariamente pelos jornalistas, mesmo quando não é tematizado. Da seleção do que fará, ou não, parte do noticiário, passando pela hierarquização e nomeação do que foi selecionado, até a edição dos fenômenos relatados, o jornalista sempre conta com uma visão de como se estrutura e se organiza o mundo em que vivemos e com uma consequente suposta melhor maneira de se acessar e reproduzir as ocorrências de interesse jornalístico. O objetivo deste artigo é apresentar os principais argumentos de duas respostas para o problema da objetividade jornalística: o realismo e o perspectivismo. Esses são dois caminhos bastante distintos no que diz respeito aos posicionamentos ontológico, epistemológico e metodológico com os quais se procura esclarecer o que está em jogo no processo de produção de notícias.

Palavras-chave: Realismo; Perspectivismo; Objetividade Jornalística; Searle; Nietzsche. 
Abstract: From the simplest to the most complex operations carried out by journalists in their daily practice, the issue of objectivity is called into question, even when it is not the main concern. By the means of selecting of what will (or will not) be part of the news, hierarchizing and editing content, and characterizing the phenomena reported, journalists have always uphold a certain perspective about how the world is structured and organized, and therefore promoted a "better way" to access and reproduce newsworthy events. This paper aims to present the main arguments behind two responses to the issue of journalistic objectivity: realism and perspectivism. Both responses entail very different ontological, epistemological and methodological positions concerning what is at stake in the news production process.

Keywords: Realism; Perspectivism; Journalistic Objectivity; Searle; Nietzsche.

\section{Introdução}

$\mathbf{O}$ objetivo deste artigo é apresentar os principais argumentos de duas respostas para o problema da objetividade jornalística: o realismo e o perspectivismo. Esses são dois caminhos bastante distintos no que diz respeito aos posicionamentos ontológico, epistemológico e metodológico com os quais se procura esclarecer o que está em jogo no processo de produção de notícias. De um lado, conhecer é dar conta daquilo cuja natureza e constituição é anterior ao processo de produção de conhecimento. Sendo assim, a meta e o objetivo de toda notícia verdadeira é essa suposta anterioridade. De outro lado, os dois termos da relação de conhecimento, sujeito e objeto, são constituídos em um único e mesmo ato: a perspectiva, que define e determina a "verdade" de todas as coisas. Nesse horizonte, conhecer é interpretar, é já estar desde sempre, em uma perspectiva com os fenômenos. Daí que a "boa" notícia passaria a ser aquela que ao mesmo tempo em que procura explicitar o maior número de perspectivas possíveis para o mesmo "fato", deixa claramente indicado desde que perspectivas é que se está construindo a informação. 
Esta investigação se justifica pelo fato de que desde a mais simples até a mais complexa operação realizada diariamente pelos jornalistas, se faz presente o problema da objetividade jornalística, mesmo quando não é tematizado. Da seleção do que fará, ou não, parte do noticiário, passando pela hierarquização e nomeação do que foi selecionado, até a edição dos fenômenos relatados, o jornalista sempre conta com uma visão de como se estrutura e se organiza o mundo em que vivemos e com uma consequente suposta melhor maneira de se acessar e reproduzir as ocorrências de interesse jornalístico.

\section{O realismo e a defesa da objetividade jornalística.}

Num primeiro horizonte, ontologicamente o mundo se realiza desde a separação sujeito e objeto, ou seja, essas duas instâncias são originariamente autônomas e se constituem anteriormente às experiências. Sendo assim, conhecer corretamente a realidade é conhecer a sua dimensão objetiva nela mesma, isto é, independentemente da sua relação com quaisquer que sejam os sujeitos e esse conhecimento é possível, já que é, e precisa ser acessível a nós. Logo, todo o esforço metodológico do jornalista deve ser o de livrar a relação, com os acontecimentos de interesse jornalístico, de qualquer interferência subjetiva, para não macular aquilo que possui uma existência independente de nós e anterior aos sujeitos cognoscentes: a realidade objetiva. É nesse primeiro horizonte que localizamos os trabalhos de Tambosi (2003) e Gauthier (2015).

A partir do pensamento de Searle, Tambosi (2003) afirma que, ontologicamente, "planetas, montanhas e rios têm um modo de existência objetivo, independente do observador; pensamentos sentimentos e dores têm modo de existência subjetivo, dependente do sujeito que os experimenta" (Tambosi, 2003, p. 44). Trazendo a discussão epistemológica para o campo do jornalismo, o autor afirma categoricamente que: "Ora, objetivo é o sujeito (jornalista ou cientista) que tende a julgar pelos fatos, sem se deixar influenciar por sentimentos, preconceitos ou predileções" (Tambosi, 2003, p. 46). Desse modo, os métodos jornalístico e científico são justamente uma tentativa 
de separar o que é opinião, um juízo do sujeito, daquilo cuja existência é inegável, já que independe dos julgamentos daqueles para quem os fenômenos se realizam.

O autor chega a essa conclusão a partir de um esforço para determinar uma epistemologia do jornalismo. O que ele procura é uma descrição filosófica criteriosa para o jornalismo como forma de conhecimento e começa a reflexão se perguntando se a realidade que é relatada pela atividade tem um estatuto ontológico diferente da ciência ou da filosofia. Apesar de reconhecer que muitos estudos já deram conta de descrever e definir as técnicas jornalísticas, falta a mesma clareza em relação aos conceitos fundamentais ligados à atividade, como por exemplo, objetividade, verdade e fato. É na discussão desses conceitos que a sua investigação quer caminhar.

Na avaliação de Tambosi (2003), as teorias do jornalismo e da comunicação são, em sua maioria, contrárias à ideia de objetividade por considerá-la uma meta inalcançável, já que ela seria equivalente à crença em uma relação de espelhamento do real realizada pelo sujeito. Tambosi identifica que prevalece, nessas críticas, o horizonte construtivista, para o qual a realidade é sempre construída socialmente. Para o construtivismo, a objetividade muitas vezes é reduzida a mero ritual estratégico dos jornalistas, ou até mesmo é utilizada como instrumento ideológico das classes dominantes (Cf. Genro Filho, 2012). Mas, para Tambosi, essa visão do realismo é distorcida, pois apresenta a sua versão mais ingênua. O autor, ao contrário, defende o realismo empírico como sendo a abordagem mais adequada para se explicar a relação entre jornalismo e realidade: "Reivindicando a independência do real, a teoria referencial do pensamento e a teoria da verdade como correspondência, o realismo permite esclarecer conceitos complexos e tão mal compreendidos como, notadamente, os de objetividade e fato" (Tambosi, 2003, p. 42).

Tambosi argumenta que o problema da cisão entre sujeito e objeto não pode ser resolvido por meio de soluções fáceis. Se por um lado, o autor concorda que o positivismo priorizava, e até mesmo sacralizava, o objeto, o idealismo, por sua 
vez, pesa exageradamente a balança para o lado do sujeito, o que resulta no relativismo mais exacerbado.

De qualquer modo, tenha-se presente que é o nosso conhecimento que faz emergir diante de nós essa realidade objetiva, um mundo já constituído, e que assim era antes que o conhecêssemos. Podemos afirmar que o mundo é real e independente de nós só porque assim o conhecemos, mas isso não nos autoriza a concluir, de maneira idealística, que as coisas são assim por efeito de nosso conhecimento (Brena, 2003, p. 243) (Tambosi, 2003, p. 43).

Isso quer dizer que, para Tambosi, ontologicamente não existe dúvida alguma da separação entre sujeito e objeto. Apesar de desempenhar papel ativo no processo de conhecimento, não é o sujeito que produz a realidade que conhece, pois ela já estava lá, do mesmo modo e estrutura que posteriormente são descobertos pelo sujeito do conhecimento. Uma sentença pode até ser considerada subjetiva, se, por ventura, expressar uma opinião, uma questão de gosto ou juízo. Desse modo, por exemplo, dizer que o trabalho de Tambosi foi publicado no segundo semestre de 2003, na Revista Brasileira de Ciências da Comunicação, é uma afirmação objetiva, visto que não expressa uma opinião pessoal e pode ser facilmente verificada e confirmada na realidade objetiva. Por outro lado, a sentença "Este texto de Tambosi é pior que o de Gilles Gauthier" é subjetiva, uma vez que expressa a avaliação de algum sujeito e não pode ser verificada objetivamente na realidade.

Nessa abordagem, até mesmo os fatos podem ser classificados entre fatos brutos, que correspondem à realidade física, natural e independente do observador, e fatos sociais e institucionais, cuja existência depende de sujeitos que organizem e ressignifiquem a objetividade. "Em outras palavras, não há fatos sociais e institucionais sem fatos brutos. Para se 'construir' dinheiro, propriedades e linguagem, [...] é necessário partir de materiais brutos como pedaços de metal, papel, terra, sons e sinais" (Tambosi, 2003, p. 44). O que Tambosi quer chamar a atenção, via Searle, é que por mais que exista uma forte relação, e mais que isso, por mais que a própria existência dos fatos sociais dependa necessariamente dos sujeitos, isso não os torna ontologicamente subjetivos. "Fatos sociais e institucionais 
são, portanto, tão objetivos quanto os fatos brutos" (Tambosi, 2003, p. 45).

É nesse sentido que o trabalho de Tambosi pretende ser uma defesa da objetividade jornalística, por meio do realismo empírico. Isso porque, mesmo quando relata fatos sociais e institucionais, o jornalista tem sempre a possibilidade de se conduzir pela objetividade, por aquilo que está no fundo das realidades socialmente construídas, quando livra-se de seus preconceitos e prejulgamentos. E quanto menor for a dependência do jornalista de fontes e versões, maior será o grau de objetividade alcançado. Dessa maneira, o jornalismo investigativo é, para o autor, o que possui maior possibilidade de realizar esse ideal de produzir um relato que revele corretamente, e verdadeiramente, a realidade, isto é, a objetividade nela mesma, autônoma e independente dos sujeitos.

Ainda neste mesmo horizonte de resposta para o problema da objetividade, apresentamos o artigo de Gilles Gauthier (2015), que também defende a busca pela objetividade jornalística por meio do realismo de John Searle. Para o autor, produzir sentenças verdadeiras é igual a alcançar a objetividade, e constitui-se uma necessidade primeira; e mais que isso: é uma premissa da atividade jornalística. Epistemologicamente, o jornalismo informa, produz conhecimento sobre a atualidade. Isso quer dizer que existe uma realidade bruta, uma série de fenômenos dados, que são objetos de cobertura por parte da mídia, ou seja, ontologicamente, os fatos, que são a matéria prima para o jornalismo, têm existência anterior aos relatos da atividade. O objetivo do artigo é demonstrar que se o papel do jornalismo é informar fielmente os fatos, a atividade não pode deixar de apreender a objetividade, isto é, a verdade, independentemente de interpretações, análises ou comentários. O argumento é o de que "[...] as relações necessárias do Jornalismo com a verdade e a realidade são tão intuitivas quanto a informação a priori que lhes serve de base" (Gauthier, 2015, p. 206).

Assim como Tambosi, Gauthier também aponta o construtivismo como o principal responsável pela crise e confusão que as ideias de objetividade e verdade têm passado nos meios 
acadêmicos na atualidade e indica que falta clareza aos jornalistas, e até mesmo aos estudiosos da atividade, quanto a essas noções, que são fundamentais para o jornalismo. O autor argumenta que a ideia de construção da realidade social não deve ser elevada a uma chave de resposta que explica toda a existência. Isso porque se é verdade que o mundo em que vivemos é, em parte, construído pela ação humana, essa construção não é completamente livre para os sujeitos fazerem o que bem entenderem, mas é realizada desde fatos concretos, a partir de uma realidade objetiva primária.

Gauthier é defensor do realismo jornalístico, baseado na filosofia de John Searle, que pode ser resumido em duas sentenças relativas à sua relação com a realidade e com a verdade:

1) Existe uma realidade independente do Jornalismo e é sobre esta realidade independente que trata, em última instância, o Jornalismo. É a partir desta realidade independente que provêm a construção jornalística. [...] 2) O Jornalismo consiste na produção de asserções verdadeiras sobre esta realidade independente. A atribuição de valor de verdade é atividade anterior à construção jornalística (Gauthier, 2015, p. 208).

Em sua argumentação, Gauthier inverte as duas proposições: é porque o jornalismo procura a verdade que o mundo precisa ser objetivamente dado, para que o jornalista possa alcançar essa realidade. A partir da teoria dos atos de fala de Searle, Gauthier argumenta que a função de informar localiza-se dentro da categoria de atos assertivos, isto é, atos que pretendem, de algum modo, "representar um estado de coisas" (Gauthier, 2015, p. 209). Os atos de fala assertivos referemse ao mundo exterior, e, portanto, possuem justamente uma necessidade de ajuste linguagem-mundo. $O$ ato de fala será mal ou bem sucedido a partir da relação entre o enunciado e o mundo exterior. Assim, uma notícia, como ato de fala assertivo, será verdadeira, se, e somente se, for adequada ao estado de coisas que relata. Uma reportagem que aponte que a maioria das pessoas no Brasil é a favor da legalização do aborto, por exemplo, será verdadeira se, efetivamente, a maioria dos brasileiros estiver de acordo com a legalização da prática. Dessa maneira, para Gauthier, não basta que o relato jornalístico seja 
honesto, equilibrado ou justo, ele precisa ser, necessariamente, verdadeiro, precisa corresponder a uma realidade objetiva pré -estabelecida. Entretanto:

Para ele [Searle], dizer que um enunciado usado para realizar um ato de fala assertivo é verdadeiro não significa dizer que ele é um espelho da realidade que representa. É, mais uma vez tecnicamente, constatar que o enunciado é bem-sucedido ao representar a realidade do fato que ocorreu efetivamente tal como indica o enunciado (Gauthier, 2015, p. 210).

Gauthier nos alerta também que a produção de sentenças verdadeiras por parte do jornalismo é uma exigência lógica da atividade e não uma constatação de que ele produz apenas notícias verdadeiras. Isso quer dizer que produzir relatos que condizem estruturalmente com o mundo objetivo é uma premissa, uma meta do jornalismo que nem sempre consegue ser atingida. Mesmo assim, a partir da teoria dos atos de fala, não se pode duvidar da missão, e mesmo vocação do jornalismo de apreender corretamente a realidade exterior por meio da linguagem. É que "[...] para considerar que a verdade nos enunciados assertivos dependa de sua correspondência aos fatos, deve-se [consequentemente] admitir que estes fatos existem independente dos enunciados" (Gauthier, 2015, p. 211).

O único argumento crítico ao construtivismo e a favor do realismo apresentado por Gauthier é o que procura desconstruir a ideia de relatividade conceitual. Segundo essa noção, a prova de que o jornalismo não pode se referir a uma realidade exterior pré-existente é que um mesmo evento ou acontecimento pode ser lido e representado de diversos modos possíveis a depender do jornalista, do veículo para o qual ele trabalha, da seleção de determinados aspectos da situação entre outras condicionantes. Esse horizonte ressalta o caráter construtivista do processo de apreensão da realidade em detrimento de uma representação pura e simples da realidade exterior objetiva. Entretanto, para Gauthier, a pluralidade de leituras possíveis para o mesmo acontecimento ao invés de depor contra o realismo, reforça a sua "evidência". É que segundo o argumento do autor, só pode haver interpretações diferentes para o mesmo fato, se 
houver uma realidade objetiva anterior, que serve de fonte para as diversas perspectivas sobre o que ocorreu.

\begin{abstract}
Searle, na verdade, não tem a pretensão de fornecer evidências para a realidade externa. Não lhe parece possível conduzir uma demonstração convincente da existência de uma realidade exterior independente das representações humanas, assim como também não o é, evidentemente, estabelecer a sua não-existência. Segundo ele, o realismo não é uma tese ou mesmo uma hipótese, mas, fundamentalmente, a própria condição de formulação de teses e hipóteses (Gauthier, 2015, p. 213).
\end{abstract}

A grande limitação do realismo jornalístico proposto por Gauthier é que não há uma reflexão propriamente filosófica que justifique a existência de uma realidade anterior ao relato jornalístico. $\mathrm{O}$ argumento lógico utilizado é bastante frágil: se o papel do jornalismo é informar, ele deve informar os acontecimentos cuja natureza é autônoma e independente dos jornalistas. Caberia aqui uma discussão muito mais profunda sobre a natureza do que é informar e até mesmo do que é a verdade. Desse modo, o autor realiza um salto muito grande e muita coisa fica sem a devida explicação. Ele toma como pressuposto óbvio e evidente que, se o papel da imprensa é informar, não pode haver interpretação alguma no relato jornalístico, logo sua meta é a objetividade autônoma e independente. Fica por se explicar melhor se a realidade é mesmo estruturada desde a separação sujeito e objeto. Essa discussão ontológica precisaria ser feita, como forma de superar esse dualismo metafísico que opõe de um lado o que são os jornalistas e de outro campo oposto o que são os acontecimentos relatados pelos jornalistas.

\title{
O perspectivismo: por uma outra “objetividade”.
}

Acreditamos que a pesquisa em Teorias do Jornalismo não pode tomar como óbvia e evidente a compreensão ontológica que divide a realidade em dois polos opostos: a objetividade e a subjetividade. Isso quer dizer que, antes de qualquer coisa, discutir a noção de objetividade jornalística é investigar o modo como ontologicamente a realidade se estrutura. É desde a pergunta pela gênese do real, pelo solo de existência, que se deve 
começar qualquer que seja a pesquisa sobre esse que é um dos conceitos mais fundamentais da atividade, já que orienta não somente a produção, como também a própria recepção dos discursos jornalísticos pelos cidadãos. É esse o esforço que pretendemos realizar na proposição de outra resposta para o problema da objetividade: desde outra ontologia, passar a compreender a objetividade jornalística de uma maneira não metafísica.

Se admitirmos como pressuposto que os acontecimentos jornalísticos têm uma organização em si mesma, pronta e acabada, antes mesmo da relação que esses fatos vão ter com os jornalistas, passa a ser vocação e até mesmo obrigação do jornalista realizar todos os esforços para "descobrir" isso cuja constituição é autônoma e diferente daquilo que o próprio jornalista é. Produzir informações com qualidade, com o compromisso com a verdade, passaria a ser, então, superar o seguinte desafio: como uma espécie de interioridade, o sujeito jornalista, pode captar e representar, de modo certo e seguro, a exterioridade: fatos e acontecimentos cuja natureza não somente é diferente, como também é oposta àquilo que é o sujeito?

Vimos que, para o realismo, esse desafio pode ser vencido, se, por meio do emprego da linguagem correta, os jornalistas conseguirem eliminar todas as interferências subjetivas no relato dos acontecimentos, na representação da própria objetividade. A realidade em si mesma é uma missão não somente possível como também necessária. Neste caminho, a origem de toda realidade, o solo ontológico da existência é justamente a cisão sujeito e objeto e a questão da objetividade jornalística deve ser atacada de forma a tentar reunir aquilo que está separado desde a sua origem.

Mas e se, como esboçamos anteriormente, começarmos a investigação questionando justamente esse pressuposto, qual seja, o de que a origem de toda realidade é a separação sujeito e objeto? Consideramos que o trabalho de Gomes (2009) é o mais consistente na tarefa de tentar superar essa separação metafísica e responder ao problema desde outros horizontes ontológico e epistemológico. Principalmente via Nietzsche, Gomes realiza o retorno necessário para que se possa tematizar com propriedade o problema do fundamento da existência e pro- 
põe o perspectivismo como modo de estruturação da realidade. Sua mais importante contribuição é exatamente trazer a noção de perspectiva como gênese de real, como forma de superar o realismo ingênuo, que não somente acredita na anterioridade dos fatos, como também na possibilidade de se apreendê-los fielmente. Entretanto, por outro lado, a saída encontrada por Gomes (2009) para não cairmos em subjetivismos, para não perdermos a possibilidade de distinguir o que é verdade e o que é mentira, parece fazer recuperar uma ideia de primeiridade da objetividade. A ideia de alcançar "o sentido próprio de um fato" (Gomes, 2009, p. 64), por meio de uma comunidade ilimitada da comunicação, parece supor que os fatos não são um produto de uma perspectiva, de uma interpretação que se realizou e que tornou possíveis o aparecimento tanto do sujeito (jornalista, enquanto jornalista) quanto do objeto (os fatos de interesse jornalístico, na forma como fatos jornalísticos aparecem). Procurar um sentido próprio dos eventos jornalísticos dá a impressão de que novamente se está pressupondo uma organização autônoma e independente não somente do objeto como também do sujeito.

Na nossa avaliação, é preciso que se rompa definitivamente com a ideia de que o real pode ser compreendido desde a cisão sujeito e objeto como gênese de toda a realidade possível. Como também parte dessa separação metafísica e é desde ela que Gomes (2009) edifica toda a sua argumentação, o trabalho não consegue superar esse erro inicial e termina confundindo a negação da objetividade como sendo uma perigosa afirmação da subjetividade e, em última instância, acaba defendendo uma perspectiva ontológica carregada de certa nostalgia da objetividade como fonte certa e segura de verdade. Porém, entendemos que essa análise é fruto de uma má-compreensão do que venha a ser interesse, perspectiva, como solo ontológico de existência.

Baseados em Nietzsche (2008), gostaríamos de propor que tanto os fatos (objeto), quanto os próprios jornalistas (sujeito) são forjados em uma relação específica; são o resultado de uma perspectiva que define não somente um modo "mais correto" de compreensão e de relato da realidade, como também determina o que é ser, pensar e agir como jornalista. Esse 
horizonte de análise parte do entendimento de que sujeito e objeto não são preexistentes à relação, mas são termos cuja constituição é resultado de uma mesma origem instauradora: a perspectiva. Não se trata de negar as ideias de sujeito e objeto, mas sim de reconhecer que elas são apenas derivadas, são tardias e não primárias e imediatas. Isso só se faz possível quando se pergunta pela efetiva gênese desses dois termos da relação, pela sua verdade ontológica.

O real - o que inclui os fatos jornalísticos - não é um "em si" anterior a toda experiência e que sempre subsiste a ela. Para Nietzsche, não há, de um lado, um sujeito fadado a conhecer e, de outro, o objeto que oferece a sua "mesmidade" para ser conhecida. Mais uma vez, não se trata de negar a contraposição sujeito-objeto, mas sim de afirmar que sua constituição não tem nada de óbvio e imediato e que esses, e outros pares opostos, não são originários e, portanto, não devem servir de parâmetro e critério para a determinação da realidade.

O que é originário e arcaico são as interpretações possíveis, ou seja, ontologicamente, em vez de haver de um lado acontecimento jornalístico como objeto em si mesmo, e, de outro, jornalista como sujeito anterior a qualquer que seja a experiência, há uma perspectiva que torna os dois termos da relação possíveis de se realizar. Com efeito, é sempre desde interesse jornalístico que jornalista vem a ser um sujeito que acredita que tudo aquilo que é trágico tem mais valor do que o que não é, e que acidente de trânsito com vítimas vem a ser notícia jornalística, na forma como diariamente vem a ser, para dar apenas um exemplo.

O famoso fragmento póstumo de Nietzsche no 481 apresenta justamente a ideia de que não existem fatos em si mesmos, somente interpretações, mas destaca que, por outro lado, a interpretação não é do sujeito, visto que o autor também nega a possibilidade de que tudo seja determinado subjetivamente.

Contra o positivismo, que fica no fenômeno "só há fatos", eu diria: não, justamente não há fatos, só interpretações [Interpretationen]. Não podemos verificar nenhum fato "em si": talvez seja um absurdo querer tal coisa.

“Tudo é subjetivo", dizeis: mas já isso é interpretação [Auslegung]. O "sujeito" não é nada de dado, mas sim algo a mais inventado, 
posto por trás. - É afinal necessário pôr o intérprete por trás da interpretação? Isso já é poesia, hipótese.

Tanto quanto a palavra "conhecimento" tem sentido, o mundo é conhecível: mas ele é interpretável de outra maneira, ele não tem nenhum sentido atrás de si, mas sim inúmeros sentidos. "Perspectivismo".

Nossas necessidades são quem interpreta [auslegen] o mundo; nossas pulsões e seus prós e contras. Cada pulsão é uma espécie de ambição despótica [Herrschsucht], cada uma tem a sua perspectiva, perspectiva que a pulsão gostaria de impor como norma para todas as outras pulsões (Nietzsche, 2008, § 481).

O fragmento recusa a concepção metafísica para o modo como o real se estrutura e se realiza, se opondo à explicação de que, em sua origem, o mundo é resultado da divisão de duas "essências" distintas e independentes: sujeito e objeto. O filósofo nos indica outro caminho de compreensão ontológica: o que seria primeiro, ou seja, o verdadeiro solo da existência residiria na interpretação. Já na primeira linha, Nietzsche deixa claro que pretende combater abertamente o positivismo, quando este horizonte afirma que "só há fatos" (Nietzsche, 2008, § 481). Para o filósofo, defender a possibilidade de verificação e comprovação de fatos "em si", autônomos e separados de uma perspectiva, "talvez seja um absurdo" (Nietzsche, 2008, § 481). Isso porque, nesse entendimento, não é possível haver nenhum fato sem que antes uma interpretação já tenha se realizado, sem que uma perspectiva, isto é, um interesse possível, tenha se apresentado para nós. Dessa maneira, podemos concluir que somos o lugar de todo o acontecimento possível, mesmo que o homem não seja o responsável, a razão ou a causa de tudo aquilo que aparece.

Para se esquivar dessa possível má compreensão subjetivista, que costuma aparecer quando se nega a objetividade positivista, Nietzsche abre aspas no texto para indicar uma reação hipotética que esse outro entendimento ontológico pode provocar. O fragmento usa desse recurso estilístico como forma de se adiantar às possíveis reações que o perspectivismo tende a suscitar. Apressadamente, pode-se concluir que, se toda a realidade não passa de interpretações, então, "Tudo é subjetivo" (Nietzsche, 2008, § 481). Anteriormente já apontamos 
que essa inferência é equivocada e só pode resultar do não entendimento do que se está querendo apontar com a crítica ao positivismo. No perspectivismo, ao contrário, até mesmo para se defender a leitura subjetivista do mundo, é, antes, necessário que uma perspectiva já tenha se apresentado para nós, já tenha se interposto e criado a possibilidade de que a realidade apareça de modo subjetivo. Nietzsche rejeita a ideia de que o sujeito seja uma espécie de substrato pré-determinado antes de toda experiência, e que subsistiria o mesmo a posteriori, ao afirmar que ele não é "nada de dado" (Nietzsche, 2008, § 481). Para não compreender o sujeito como uma essência de ordem primária e imediata, é preciso, em vez disso, investigar a sua natureza a partir de um parâmetro completamente diferente de determinação do real.

Podemos chamar de perspectiva, ou interpretação, esse outro lugar de definição e entendimento de origem proposto pelo filósofo. No princípio de tudo, como fonte de toda a realidade, existe a perspectiva, e nada mais, como condição de possibilidade de existência. A interpretação como solo ontológico altera também, de modo radical, a primordial tarefa do conhecimento, tornando obsoleto o problema epistemológico da ponte sujeito-objeto, uma vez que, na origem, esses dois termos não estão efetivamente divididos. Sendo assim, o mundo não deixa de ser cognoscível, mas em vez de alcançar o "sentido em si" (Nietzsche, 2008, § 481) de toda a realidade, no lugar de buscar a natureza primeira dos objetos com os quais nos relacionamos, conhecer passa a se constituir como um ato de interpretação que inaugura o real.

Antes de qualquer mal entendido, é preciso definir com clareza o lugar ao qual a argumentação apresentada até aqui nos levou. Quando afirmamos anteriormente que conhecer é interpretar o real com o qual nos relacionamos, não queremos apontar a impossibilidade de acesso a uma realidade "em si" e que, por isso, a tarefa do conhecimento deve se limitar a encontrar a perspectiva mais próxima possível dessa objetividade primeira inalcançável. A interpretação não é algo que o sujeito do conhecimento acrescenta ou descobre na suposta "objetivi- 
dade" com a qual se relaciona. Conhecer é interpretar porque a realidade é, em primeiríssima instância, uma perspectiva, uma interpretação possível. "Elas não possuem uma perspectiva, mas, antes, são essa perspectiva, um interesse que inaugura, e torna possíveis tanto sujeito quanto o próprio objeto" (Henriques, 2014, p. 101-102).

Exatamente por esse motivo, o fragmento argumenta que não há "nenhum sentido atrás de si, mas sim inúmeros sentidos. Perspectivismo" (Nietzsche, 2008, § 481). Isso porque a realidade deixa de ser compreendida como sendo o somatório das diversas "essências" perenes e imutáveis de tudo aquilo que existe. Os objetos do mundo não são mais entendidos como a manifestação aparente de uma causa ou motivo que se esconde por trás dessa aparência e que representariam o verdadeiro conhecimento. Nesse horizonte, o real não se realiza como efeito visível de uma objetividade primeira a ser descoberta, mas sempre, e a cada vez, desde um modo próprio de "ver", isto é, a partir de uma perspectiva que torna possível o aparecimento tanto do objeto, como também do sujeito. Em vez de um único sentido por trás das coisas com as quais nos relacionamos, inúmeros sentidos como causa/fundamento dessas próprias coisas. "Sentido e coisa são uma mesma realidade que se dá num único e mesmo ato" (Henriques, 2014, p. 102). É tarefa do sujeito do conhecimento, e para a discussão que nos interessa aqui, é dever do jornalista, realizar todos os esforços para explicitar as origens e as consequências das diversas interpretações que instauram o mundo em que vivemos, e que são adotadas e potencializadas pelo jornalismo na abordagem dos acontecimentos de interesse jornalístico.

Outro fragmento póstumo nietzschiano que pode nos ajudar a avançar ainda mais na explicação do perspectivismo como posicionamento ontológico e epistemológico particular é o de $\mathrm{n}^{\mathrm{o}} 555$. O jornalismo tem a pretensão de descrever a realidade de modo desinteressado e essa busca resulta até mesmo em regras e normas de conduta da profissão. Essa ambição se justifica no ideal da atividade de relatar os fatos com rigor e exatidão. Nessa lógica, os jornalistas precisariam se esforçar para não se 
envolver nos acontecimentos reportados como forma de se aproximar o máximo possível da realidade objetiva, livrando os relatos de influências e interferências subjetivas. Pois essa aspiração jornalística de conhecer desinteressadamente é justamente uma impossibilidade apontada claramente pelo fragmento:

- A maior fabulação é aquela do conhecimento. Gostar-se-ia de saber como as coisas em si são constituídas: mas veja, não há nenhumas coisas em si! E mesmo que houvesse em si, um incondicionado, então, justamente por isso, ele não poderia ser conhecido! Algo incondicionado não pode ser conhecido: senão justamente não seria incondicionado! Conhecer, todavia, é sempre "colocar-se em uma condição para com alguma coisa" - -; um tal conhecedor quer que aquilo que queira conhecer não lhe diga respeito em nada, e que o mesmo algo não diga respeito a ninguém em geral: no que, primeiramente, se dá uma contradição, a saber, no querer-conhecer e no exigir que nada deva dizer-lhe respeito (então, para que conhecer!), e, em segundo lugar, porque algo, que não diz respeito a ninguém em nada, absolutamente não é, e, portanto, também não pode ser conhecido. - Conhecer quer dizer "colocar-se em uma condição em relação a algo": sentir-se condicionado por algo e entre nós - - é, portanto, sob todas as circunstâncias, um estabelecer, designar, tornar-se consciente de condições (não um sondar as essências [Wesen], coisas, "em-si”) (Nietzsche, 2008, § 555).

Por meio de um argumento relativamente simples, mas contundente, o fragmento reforça a crítica ao entendimento de que o verdadeiro conhecimento deve se empenhar em descobrir o que são as "coisas em si". A intenção do texto é desconstruir a compreensão de que um atributo de essência seja a causa de tudo aquilo que se manifesta e que, para acessar essa determinação última de todas as coisas, o sujeito não pode tomar parte no processo de conhecimento. Quando consegue livrar a existência das influências ou máculas subjetivas, o homem poderia, nesse horizonte, revelar corretamente aquilo que permanece sempre o mesmo e cuja existência independe de contexto e conjuntura: a objetividade. Só que para Nietzsche, não pode haver nenhuma realidade sem que ocorra ocasião e circunstância, já que é justamente a perspectiva, e não uma suposta essência, que torna possível e que realiza o aparecimento de mundo. Pela lógica, mesmo que houvesse um "incondicionado", ele "não poderia ser conhecido!" (Nietzsche, 2008, § 555). É que se algo não diz respeito a nada e a ninguém, desaparece 
aquilo que é a condição de possibilidade da sua existência: a relação. Sem essa premissa não se pode nem mesmo nomear o que quer que seja. "Seu próprio modo de ser [do "incondicionado"], sua realidade ontológica seria justamente o motivo que impediria definitivamente que pudéssemos conhecê-lo em qualquer que fosse a medida" (Henriques, 2014, p. 102).

Nietzsche argumenta ainda que, em vez de "sondar as essências", revelar o que "não diga respeito a ninguém em geral" ou acessar o "incondicionado", conhecer é justamente "colocar-se em uma condição para com alguma coisa" (Nietzsche, 2008 , § 555). Isso quer dizer que não há conhecimento imaculado! Conhecer é sempre, e a cada vez, o resultado de uma determinada perspectiva que se estabelece, e que, por sua vez, está circunscrita a certa ocasião ou conjuntura que inauguram e condicionam os dois termos da relação. Sendo assim, não há nenhuma forma de acesso à realidade que seja desinteressada ou que se efetive fora de qualquer que seja a perspectiva. Determinar as causas e consequências de fenômenos sociais ou naturais, classificar ou categorizar os seres e objetos presentes na natureza, ou mesmo descrever com rigor e precisão os fatos objetos de atenção jornalística, são sempre operações que dependem, necessariamente, que uma relação qualquer já tenha se estabelecido, que uma perspectiva tenha se interposto primeira e imediatamente, de maneira a determinar, inclusive, a forma como sujeito e objeto vêm a aparecer. "Querer uma "coisa em si" seria querer que algo seja fora de toda e qualquer relação possível, ou seja, é querer que as "coisas" sejam desprovidas justamente daquilo que faz com que elas sejam, apareçam, se manifestem e se mostrem para nós" (Henriques, 2014, p. 103).

Na compreensão nietzschiana, o ato de conhecer "é, portanto, sob todas as circunstâncias, um estabelecer, designar, tornar-se consciente de condições (não um sondar as essências [Wesen], coisas, 'em-si')" (Nietzsche, 2008, § 555). A transformação é radical e traz consequências não somente para a filosofia e a ciência, como também para a atividade jornalística. Em vez de focar o trabalho na busca pelos fatos "em si", independentemente de interpretação, o jornalista deveria procurar 
explicitar justamente as condições que regulam a perspectiva desde a qual o seu relato se tornou possível. O jornalista nunca revela, nem mesmo se aproxima da objetividade, mas sempre interpreta os acontecimentos de interesse jornalístico. A tarefa passa as ser, então, "[...] procurar as condições, o interesse e a perspectiva que se realiza e que é justamente o que guia e governa o modo como cada uma das possibilidades do real se mostra e se efetiva" (Henriques, 2014, p. 103).

No jornalismo, o fato, que costuma ser compreendido como equivalente a objetividade nela mesma, e a perspectiva, que costuma ser entendida como um elemento posterior que é acrescentado pela subjetividade do jornalista, são, na verdade, ontologicamente uma mesma realidade que se dá num único e mesmo ato. Na perspectiva jornalismo, tanto os acontecimentos quanto os jornalistas se realizam e se configuram de uma certa, e não de outra, maneira. Os dois termos só são desde essa perspectiva inaugural.

Trazendo ainda mais a reflexão para o campo do jornalismo, podemos dizer que, se ontologicamente não há "coisas em si", procurar a objetividade dos acontecimentos de interesse jornalístico, entendendo a objetividade como essência daquilo que ocorreu, passa a ser a mais pura ficção. Um grave erro de origem. Isso porque, em tudo o que é e se realiza, não existe apenas um sentido, mas diversos sentidos possíveis, as mais variadas perspectivas. Sendo assim, o relato que procura aparentar desinteresse é apenas mais um dos horizontes possíveis de interpretação do que aconteceu, que produz verdade ao seu modo, de maneira específica. E é essa especificidade que configura esse modo de aparecimento desde a perspectiva que jornalismo inaugura.

O jornalismo, como interesse possível, é uma perspectiva que, desde o aparente desinteresse, oferece lugar e oportunidade para que os diversos sentidos possíveis de um determinado fenômeno ganhem visibilidade. Epistemologicamente, podemos afirmar que a atividade, desde uma estratégia de invisibilidade, conhece o real a partir de uma relação que assume uma ou mais interpretações possíveis para um mesmo aconte- 
cimento e as apresenta, muitas vezes, como sendo a "realidade nela mesma", sem mediação. Se o real são as variadas perspectivas de algo que é ou que ocorreu, o jornalista precisa expor o maior número possível de horizontes de interpretação do que está relatando como forma de tentar dar conta da multiplicidade, dessa "outra essência" de tudo que se realiza. O desafio diário da atividade jornalística deixa de ser espelhar o real ou representar de modo fiel, ou mais fiel possível, os acontecimentos do dia-a-dia. Na maioria dos casos, o mais difícil é conseguir apresentar uma perspectiva do que aconteceu que supere ou subverta o senso comum, a versão majoritária dos fatos e ocorrências de interesse jornalístico.

\section{Considerações finais}

Mas em que essa segunda resposta para a questão difere da estratégia de "objetividade" de ouvir o outro lado; de reportar as diversas versões de um mesmo acontecimento? A principal diferença é de ordem ontológica e epistemológica. Nesse horizonte, o jornalista deixaria de achar que deve alcançar a objetividade ou chegar o mais próximo possível dela simplesmente porque a objetividade deixa de ser o parâmetro da verdade, deixa de ser sinônimo de fundamento de tudo o que ocorre. A "essência" de tudo o que se realiza passa a ser as diversas relações possíveis com os fatos com os quais nos relacionamos e é por isso que a dinâmica desde a qual o jornalismo produz a notícia precisa ser esclarecida para o público consumidor de informação. Os fatos e ocorrências, que são objeto de interesse da atividade jornalística, são resultado do modo que o jornalismo interpreta a realidade e, dessa forma, acreditamos que os processos, crenças e valores representados por essa perspectiva precisam ser mais claros e transparentes.

Por um lado, o jornalismo como interpretação deveria assumir que sua perspectiva desinteressada é apenas mais um interesse entre muitos possíveis e, de outro, essa estratégia de se fazer "apagar" o sujeito do texto jornalístico, e toda e qualquer "interpretação", precisa ser substituída pela assunção de que a atividade sempre parte de um ou de diversos pontos de 
vista. A realidade retratada pelo jornalismo é resultado da perspectiva que serve de base para toda e qualquer leitura do mundo. É desde um argumento religioso, por exemplo, que uma reportagem pode mostrar que a distribuição de seringas a usuários de drogas pode incentivar o consumo de entorpecentes. Há verdade nesta perspectiva, como também em diversas outras. E isso precisa ser explicitamente apontado no relato jornalístico. De onde vem essa relação com a realidade? O que ela significa? Quais são suas consequências? Estamos defendendo a ideia de que o jornalista deveria sempre deixar claro qual é a perspectiva desde a qual está construindo a sua reportagem. É desde uma interpretação feminista que o aborto até a $12^{\mathrm{a}}$ semana de gestação é uma questão de direito ao corpo da mulher e é a partir da perspectiva política de direita, para dar mais um exemplo, que os movimentos sociais podem ser criminalizados, e isso deveria estar indicado no texto, com todas as letras, em vez de ser apresentado como "realidade objetiva", como os "fatos puros" ou como o mais próximo possível da verdade. Com mais transparência com relação aos seus próprios critérios e procedimentos, o jornalismo poderia contribuir para uma sociedade mais crítica e independente, capaz de identificar desde que interpretação se está construindo verdade, realidade "objetiva".

Outra pergunta que pode surgir desde esta segunda resposta ao problema da objetividade é: Por que a negação da objetividade não conduz ao arbítrio do sujeito, a um subjetivismo e relativismo absolutos, temidos por tantos autores? Se tudo são interpretações, como não concluir que a interpretação é do sujeito e depende de seus gostos, preferências e histórico de vida particulares? Essas perguntas só tem razão de ser como função retórica e didática, pois já ficou indicado anteriormente que a perspectiva não é do sujeito. Não é uma decisão do jornalista interpretar o real, pois ele sempre já se encontra desde uma interpretação, que não é dele, mas que circula entre as diversas perspectivas possíveis para o mesmo fato ou acontecimento de interesse jornalístico. Nesse sentido, a preocupação de Gomes (2009) e de outros autores não tem razão de ser. O jornalista não pode escrever qualquer coisa, interpretar ao seu modo e de acordo com as suas preferências pessoais. Ele o fará desde um 
horizonte que o toma e que realiza o que aparece como sendo isso ou aquilo. Como decisão pessoal, os jornalistas deveriam estar atentos não para apagar o seu interesse no acontecimento ou para descobrir a verdade última de todas as coisas, mas sim para, de um lado, identificar claramente a perspectiva desde a qual estão produzindo o seu relato, e, por outro, apresentar as mais variadas perspectivas possíveis para o mesmo fenômeno.

\section{Referências}

GAUTHIER, Gilles. A verdade: visada obrigatória ao jornalismo. In: Estudos em jornalismo e mídia. v.12, nº2, julho a dezembro, 2015. p. 204-215.

GENRO FILHO, Adelmo. O segredo da pirâmide. Para uma teoria marxista do jornalismo. Série Jornalismo a rigor V.6. Florianópolis: Insular, 2012.

GOMES, Wilson. Jornalismo, fatos e interesses: ensaios de teoria do jornalismo. Série Jornalismo a rigor V.1. Florianópolis: Insular, 2009.

HENRIQUES, Rafael Paes. Tecnologia, objetividade e superação da metafísica. Vitória: EDUFES, 2014.

NIETZSCHE, Friedrich. A vontade de poder. Tradução: Francisco José Dias de Moraes e Marcos Sinésio Pereira Fernandes. Rio de Janeiro: Contraponto, 2008.

TAMBOSI, Orlando. Elementos para uma epistemologia do jornalismo. In: Intercom - Revista Brasileira de Ciências da Comunicação. São Paulo, v. 26, n. 2, p 40-52, jul/dez 2003. 